\title{
Herbicide/Quinone Binding Interactions in Photosystem II
}

\author{
Wim F. J. Vermaas *,**, Gernot Renger*, and Charles J. Arntzen** \\ * Max-Volmer-Institut für biophysikalische und physikalische Chemie, Technische Universität \\ Berlin, Sekr. PC 14, Straße des 17. Juni 135, D-1000 Berlin 12, Germany \\ ** MSU/DOE Plant Research Laboratory, Michigan State University, East Lansing, \\ MI 48824, USA \\ Z. Naturforsch. 39 c, $368-373$ (1984); received December 1, 1983
}

\begin{abstract}
Herbicide, Photosystem II, Plastoquinone, Photosynthesis, Allosteric interaction
Many inhibitors prevent the oxidation of the primary electron-accepting quinone $\left(\mathrm{Q}_{\mathrm{A}}\right)$ by the secondary quinone $\left(\mathrm{Q}_{\mathrm{B}}\right)$ in photosystem II by displacement of $\mathrm{Q}_{\mathrm{B}}$ from its binding site. On the other hand, plastoquinone-1 and 6-azido-5-decyl-2,3-dimethoxy-p-benzoquinone displace herbicides. Binding studies show the herbicide/quinone interaction to be (apparently) competitive.

The herbicide binding is influenced differentially by various treatments. In this paper it is shown that the affinity of, for example, bromoxynil is decreased by thylakoid unstacking or by light- or reductant-induced reduction of certain thylakoid components, whereas atrazine affinity remains unchanged. Furthermore, absence of $\mathrm{HCO}_{3}^{-}$in the presence of formate leads to an affinity decrease of bromoxynil and atrazine, but to an increase in i-dinoseb affinity. Other differential photosystem II herbicide effects are known from the literature.

Since different and unrelated groups of $\mathrm{Q}_{\mathrm{A}}^{-}$oxidation inhibitors have been found, and because of the above-mentioned dissimilarities in binding characteristics for different inhibitor groups, the hypothesis of non-identical, but "overlapping" binding sites for different herbicide groups and the native quinone must be more extensively defined. In this manuscript we evaluate both the competitive herbicide/quinone binding model, and a model in which binding of one ligand alters the protein conformation resulting in a dramatic decrease in the binding affinity of ligands from other chemical groups; in this model ligands from the same or related chemical groups bind competitively. Thus, the latter model proposes that only one herbicide or quinone molecule can be bound with high affinity to the herbicide/quinone binding environment, but it depends on the chemical structure of the ligands whether the binding interaction between two ligands is truly competitive or more indirect (allosteric), mediated through the protein conformation.
\end{abstract}

\section{Introduction}

A large variety of different chemicals, acting as powerful herbicides, are known to block the electron transport between the primary and secondary electron-accepting plastoquinone (referred to as $\mathrm{Q}_{\mathrm{A}}$ and $\mathrm{Q}_{\mathrm{B}}$, respectively) at the Photosystem II (PS II) acceptor side (for a recent review, see [1]). $\mathrm{Q}_{\mathrm{A}}$ and $\mathrm{Q}_{\mathrm{B}}$ are inferred to be bound to functional

\footnotetext{
Abbreviations: Atrazine, 2-chloro-4-(ethylamino)-6-isopropylamino-s-triazine; bromoxynil, 3,5-dibromo-4-hydroxybenzonitrile; DCMU, 3-(3,4-dichlorophenyl)-1,1dimethylurea; i-dinoseb, 2,4-dinitro-6-isobutylphenol; durohydroquinone, tetramethyl- -benzohydroquinone; ioxynil, 3,5-diiodo-4-hydroxybenzonitrile; metamitron, 4-amino-4,5-dihydro-6-phenyl-3-methyl-1,2,4-triazin-5-one; $\mathrm{PQ}$, plastoquinone; PS, photosystem; $\mathrm{Q}_{\mathrm{A}}$, primary electron-accepting quinone; $\mathrm{Q}_{\mathrm{B}}$, secondary electron-accepting quinone; $\mathrm{Q}_{\mathrm{B}}$ protein, rapidly turned over protein $\left(M_{\mathrm{r}} \sim 32000 \mathrm{Da}\right)$ that is specifically labelled by azidoatrazine.

Reprint requests to Prof. Dr. G. Renger.

0341-0382/84/0500-0368 \$01.30/0
}

protein constituents of PS II [2]. $\mathrm{Q}_{\mathrm{B}}$ and PS II herbicides were hypothesized to bind competitively to the same binding environment $[3,4]$. Using the method of binding radioactively labelled PS II herbicides to thylakoid membranes [5], all PS II inhibitors tested, as well as an electron accepting quinone [6], were shown to replace each other (with the exception of 2-bromo-3-methyl-1,4-naphthoquinone [7]). These results and recent data analyzing the competition between herbicides and quinones [8-10] support the hypothesis of a common binding environment for $\mathrm{Q}_{\mathrm{B}}$ and PS II herbicides. This conclusion, however, does not necessarily indicate that all PS II herbicides and quinones have certain binding determinants in common as was implicated in previous models of overlapping binding sites $[11,12]$.

The construction of a comprehensive model for the binding of PS II inhibitors must consider various ways in which different chemical classes of inhibitors bind (apparently) competitive with 
respect to quinone and herbicide binding. Two primary mechanisms exist:

1) binding to physically overlapping sites so that the two compounds cannot simultaneously exist in the common site, or

2) binding to distinctly different sites such that binding of one compound causes a conformational change in the binding protein(s), thereby dramatically reducing the affinity of the second compound.

The latter possibility, obviously, could involve different binding sites either in close or distant proximity. The idea of allosteric herbicide binding is consistent with the observation that the herbicide binding affinity is affected by protein phosphorylation [13], $\mathrm{CO}_{2}$-depletion [14, 15], and covalent linkage of an azidoquinone [6].

Due to space limitations, only part of the results shown at our presentation in Wageningen can be presented here. For further details the reader is referred to [9].

\section{Materials and Methods}

The thylakoid isolation from pea leaves and from leaves of triazine-susceptible or resistant biotypes of Amaranthus hybridus L. was as in [16]. After isolation, the thylakoids were suspended in a medium consisting of $50 \mathrm{~mm}$ tricine/ $\mathrm{NaOH}, 10 \mathrm{~mm} \mathrm{NaCl}, 5 \mathrm{~mm}$ $\mathrm{MgCl}_{2}$ and $0.3 \mathrm{M}$ sorbitol, at $\mathrm{pH}=7.6$. This medium was used for the experiments unless indicated otherwise.

The herbicide binding experiments performed as described in [6] were done under controlled light intensity conditions (virtually in the dark unless indicated otherwise). In order to ensure equilibrium conditions, it was necessary to incubate the thylakoids with $\left[{ }^{14} \mathrm{C}\right]$ bromoxynil or ioxynil for at least $10 \mathrm{~min}$. For atrazine, shorter incubation times were sufficient.

For determining the binding affinity of i-dinoseb, the $\left[{ }^{14} \mathrm{C}\right]$ atrazine or $\left[{ }^{14} \mathrm{C}\right]$ ioxynil binding at ten different labelled herbicide concentrations was monitored in the absence and presence of three different concentrations of unlabelled i-dinoseb. Using the equations derived for competitive herbicide binding $[5,9]$, the dissociation constant of $\left[{ }^{12} \mathrm{C}\right] \mathrm{i}$-dinoseb was calculated. Direct measurements of radioactive i-dinoseb binding to the inhibitor/ quinone binding environment is very tricky because of the large contribution of $\mathrm{i}$-dinoseb binding to thylakoid membrane components unrelated to inhibition of electron transport (see, for example, [17]).

$\mathrm{HCO}_{3}^{-}$-depleted thylakoids were obtained by suspending thylakoids in a $\mathrm{CO}_{2}$-free medium consisting of $50 \mathrm{~mm} \mathrm{MES} / \mathrm{NaOH}, 10 \mathrm{~mm} \mathrm{NaCl}, 5 \mathrm{~mm}$ $\mathrm{MgCl}_{2}, 25 \mathrm{~mm} \mathrm{HCOONa}$ and $0.2 \mathrm{M}$ sorbitol at $\mathrm{pH}=6.0$. The thylakoid suspension was allowed to incubate for $1 \mathrm{~h}$ at room temperature in a capped tube, which was flushed previously with $\mathrm{N}_{2}$. After this incubation period, $5 \mathrm{~mm} \mathrm{NaHCO} 3$ was added to certain samples ("reconstituted thylakoids").

\section{Results}

\section{Quinone reduction by light or dithionite}

Reduction of the plastoquinone pool and $\mathrm{Q}_{\mathrm{B}}$ by durohydroquinone or dithionite leads to a marked decrease in the affinity of ioxynil, but not in that of atrazine [9]. This effect was attributed to a reduction-induced conformational change of a special region of the inhibitor/quinone binding environment. We also observed that the bromoxynil affinity was decreased upon reduction by dithionite (Fig. 1). The same affinity changes appear to be inducible by light (Fig. 1); these changes are reversible in the dark (data not shown). Therefore, the reductioninduced affinity change is unlikely to be due to a chemical reduction of bromoxynil because this reaction is expected to be irreversible. An affinity decrease upon illumination comparable to that of bromoxynil was also observed for ioxynil and i-dinoseb, whereas the binding of atrazine (and also of metamitron, W. Vermaas, W. Draber, and G. Renger, unpublished) was only slightly affected (see Table I).

\section{Divalent cations}

Grana unstacking caused by omission of $\mathrm{Mg}^{2+}$ from the solution used for thylakoid suspension and subsequent restacking by $\mathrm{MgCl}_{2}$ addition also appears to result in affinity changes of bromoxynil (Fig. 2A) and ioxynil (data not shown), whereas atrazine binding remains almost unaffected (Fig. 2B). As could be expected, the total number of herbicide binding sites is insensitive to stacking and unstacking. 


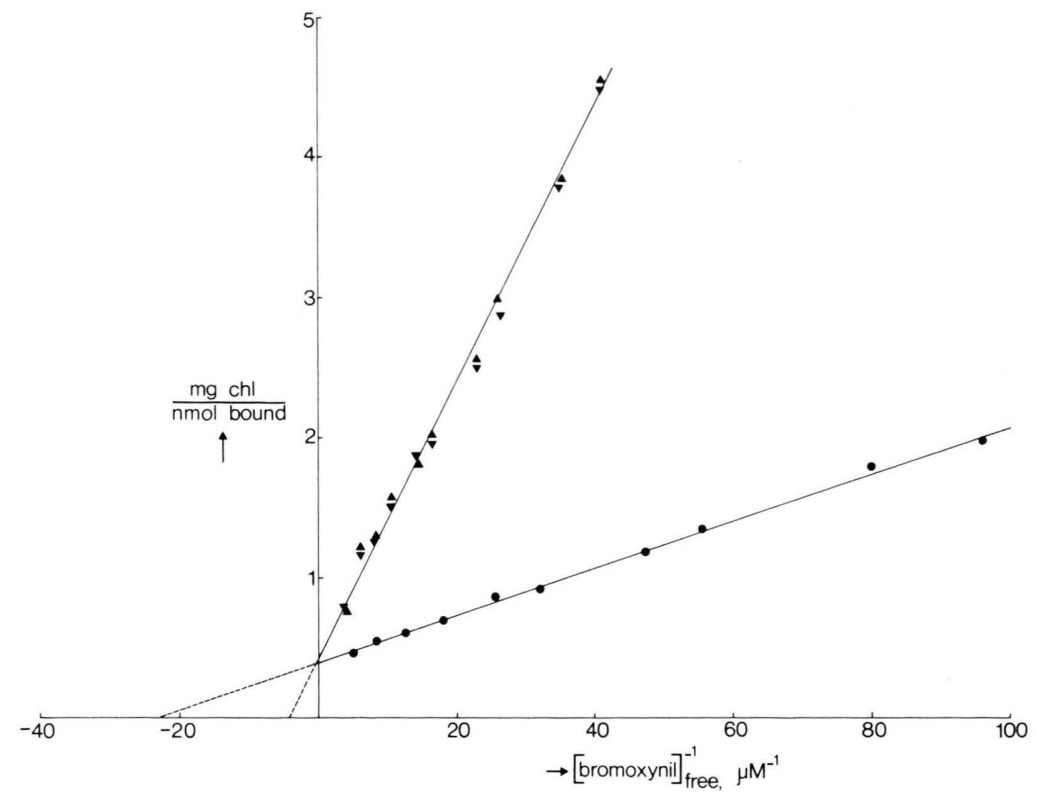

Fig. 1. Double-reciprocal plot of $\left[{ }^{14} \mathrm{C}\right]$ bromoxynil binding to pea thylakoids $\left(50 \mu \mathrm{g} \cdot \mathrm{ml}^{-1}\right.$ chlorophyll in the dark in the absence $(\bullet)$ and presence $(\mathbf{v})$ of $2 \mathrm{~mm}$ sodium dithionite and in bright room light without dithionite ( $\mathbf{\Delta}) . K_{\mathrm{d}}=45 \mathrm{~nm}$ in oxidized and $220 \mathrm{~nm}$ in reduced conditions. One bromoxynil binding site per $\sim 400 \mathrm{Chl}$ molecules.

\section{Effects of $\mathrm{HCO}_{3}^{-} / \mathrm{CO}_{2}$}

It is known that, in the presence of formate, absence of $\mathrm{HCO}_{3}^{-}$leads to a decrease in the affinity of atrazine [14] and of ioxynil [15]. We observed a considerable decrease in bromoxynil affinity upon $\mathrm{CO}_{2}$-depletion as well: in the absence of $\mathrm{HCO}_{3}^{-}$the bromoxynil dissociation constant $K_{\mathrm{d}}$ was $125 \mathrm{nM}$, whereas after addition of $5 \mathrm{~mm} \mathrm{HCO}_{3}^{-} K_{\mathrm{d}}$ decreased to $58 \mathrm{~nm}$. The number of bromoxynil binding sites did not change upon $\mathrm{HCO}_{3}^{-}$addition. In our hands the atrazine affinity was lower $\left(K_{\mathrm{d}}=225 \mathrm{~nm}\right.$ and $58 \mathrm{nM}$ in the absence and presence of $\mathrm{HCO}_{3}^{-}$, respectively) than reported by Khanna et al. [14]. Preliminary results indicate that the affinity dependence of $\mathrm{i}$-dinoseb on the presence of $\mathrm{CO}_{2}$ is opposite to that of atrazine, ioxynil or bromoxynil.

Table I. Herbicide affinity in light and in darkness. Dissociation constants $\left(K_{\mathrm{d}}\right)$ in $\mathrm{nM}$ of three herbicides in darkness and in bright room light. $50 \mu \mathrm{g} \cdot \mathrm{ml}^{-1}$ chlorophyll. Atrazine and ioxynil affinity were determined directly by binding experiments with these ${ }^{14} \mathrm{C}$-labelled herbicides; i-dinoseb affinity was determined by competition experiments of $\left[{ }^{12} \mathrm{C}\right] \mathrm{i}$-dinoseb with $\left[{ }^{14} \mathrm{C}\right]$ atrazine (see [9]).

\begin{tabular}{lcc}
\hline & Light & Dark \\
\hline Atrazine & 63 & 57 \\
i-Dinoseb & 450 & 220 \\
Ioxynil & 22 & 6 \\
\hline
\end{tabular}

At $\mathrm{pH}=6.0$, the $K_{\mathrm{d}}$ of $\mathrm{i}$-dinoseb is $30 \mathrm{~nm}$ in the absence, and $105 \mathrm{~nm}$ in the presence of $\mathrm{HCO}_{3}^{-}$. This behaviour may partially explain the seemingly competitive interaction between $\mathrm{HCO}_{3}^{-}$and 4,6-dinitro-o-cresol [18] and i-dinoseb [19].

\section{Quinone addition in triazine-resistant and-susceptible thylakoids}

As could be expected from the hypothesis of a common quinone/inhibitor binding environment, PQ-1 competes with PS II herbicides for binding. Based on competition studies between PQ-1 and $\left[{ }^{14} \mathrm{C}\right]$ bromoxynil, the apparent dissociation constant of PQ-1 was found to be $15 \mu \mathrm{M}$ in triazine-susceptible (not shown), and $20 \mu \mathrm{M}$ in triazine-resistant thylakoids (Fig. 3). Since most PQ-1 may partition into the thylakoids, it is better to express the PQ-concentration in terms of a PQ-1/chlorophyll (Chl) ratio. The $\mathrm{Chl}$ concentration was $100 \mu \mathrm{g} \cdot \mathrm{ml}^{-1}$; thus, the PQ-1/Chl ratio necessary for decreasing the bromoxynil affinity by a factor of 2 was 0.15 for triazine-susceptible and 0.20 for triazine-resistant thylakoids. On the basis of 400 chlorophylls per PS II chain and neglecting the binding of the native plastoquinone molecules, a number of $60-80 \mathrm{PQ}-1$ molecules per PS II chain is calculated to be necessary in order to occupy the herbicide binding 

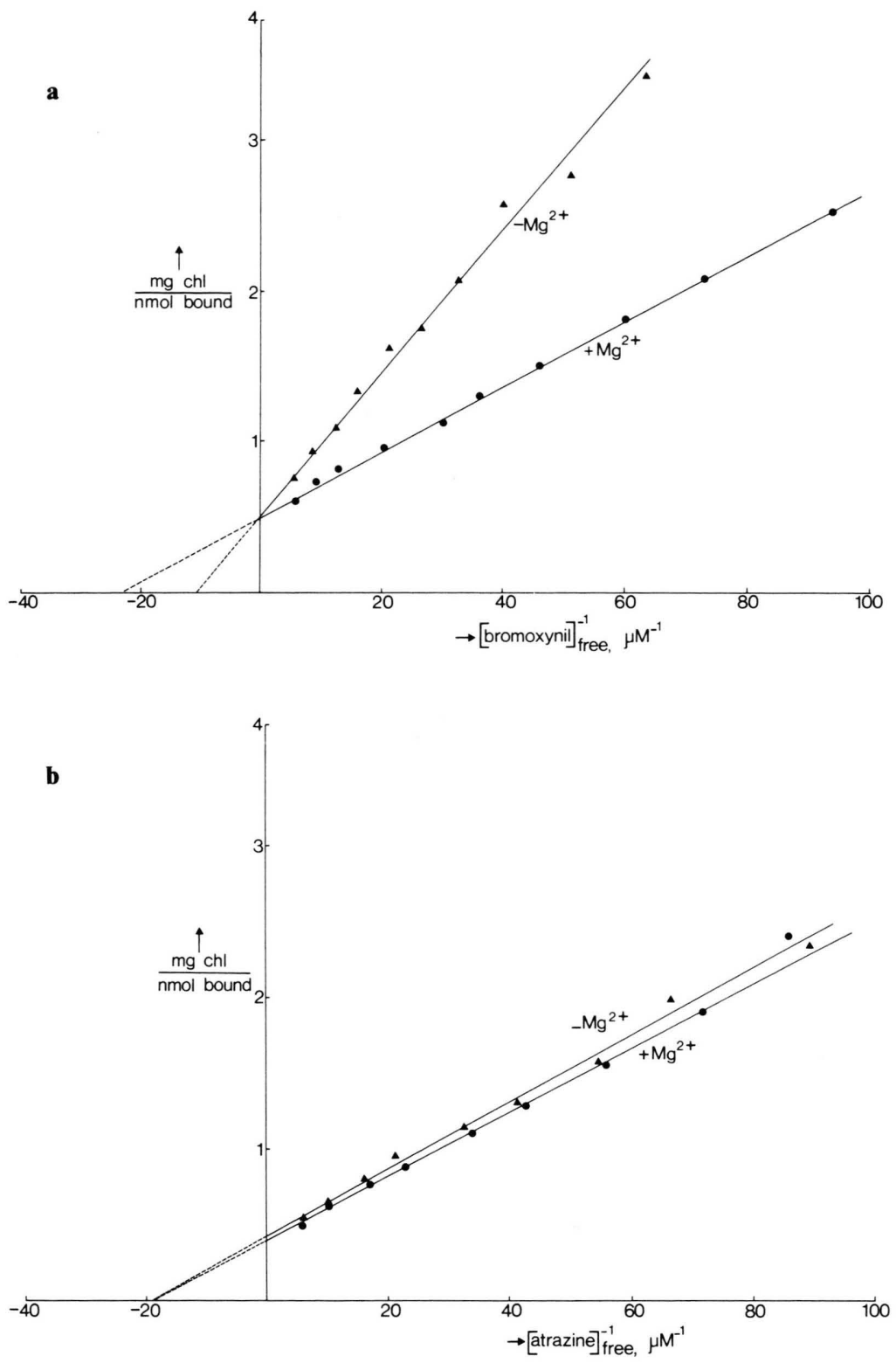

Fig. 2. Double-reciprocal plot of $\left[{ }^{14} \mathrm{C}\right]$ bromoxynil $(\mathrm{A})$ and $\left[{ }^{14} \mathrm{C}\right] \mathrm{atrazine}$ (B) binding to pea thylakoids in the dark in the presence $(\bullet)$ and the absence ( $\Delta$ ) of $5 \mathrm{mM} \mathrm{Mg}^{2+}$. The reaction medium used $(\mathrm{pH}=7.6)$ did not contain $\mathrm{Mg}^{2+}$. When necessary, $5 \mathrm{mM} \mathrm{MgCl} 2$ was added. For bromoxynil, $K_{\mathrm{d}}=45 \mathrm{~nm}$ in the presence and $93 \mathrm{nM}$ in the absence of $\mathrm{Mg}^{2+}$. For atrazine, $K_{\mathrm{d}}=53 \mathrm{~nm}$ irrespective the $\mathrm{Mg}^{2+}$. One herbicide binding site per $400-500$ chlorophyll. $50 \mu \mathrm{g} \cdot \mathrm{ml}^{-1} \mathrm{Chl}$.

environment in $50 \%$ of the reaction chains, assuming a uniform PQ-1 distribution.

Under similar conditions, 2.5 and $5 \mu \mathrm{M}$ of the synthetic electron-accepting quinone 6-azido-5-decyl2,3-dimethoxy-p-benzoquinone were required to increase the bromoxynil dissociation constant by a factor of 2 in triazine-susceptible and -resistant thylakoids, respectively. Thus, the azidoquinone has a higher affinity for the inhibitor/quinone binding environment than PQ-1.

\section{Discussion}

The results show that the affinity of PS IIdirected inhibitors to their binding environment at the PS II acceptor side is changed by various treatments. A specific treatment does not result in a similar change for different inhibitors. Under conditions leading to reduction of the plastoquinone pool (either chemically or photochemically), the binding affinity of ioxynil, bromoxynil and i-dinoseb 


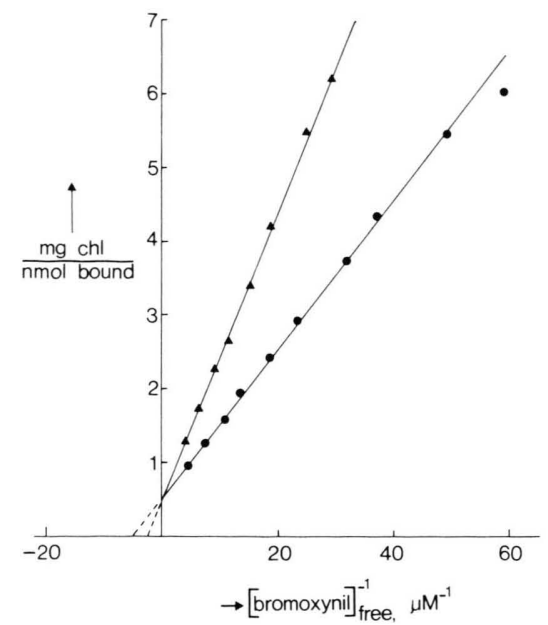

Fig. 3. Double-reciprocal plot of $\left[{ }^{14} \mathrm{C}\right]$ bromoxynil binding to triazine-resistant thylakoids from Amaranthus hybridus in the absence $(\bullet)$ and the presence $(\boldsymbol{\Delta})$ of $20 \mu \mathrm{M}$ PQ-1; $100 \mu \mathrm{g}$ chlorophyll per $\mathrm{ml}$. One bromoxynil binding site per $\sim 500 \mathrm{Chl}$ molecules; $K_{\mathrm{d}}=193 \mathrm{nM}$ in the absence and $403 \mathrm{~nm}$ in the presence of PQ-1.

decreases, while that of atrazine or metamitron remains almost unchanged. Analogous effects are observed after grana unstacking. The modification of the binding properties can be understood by conformational changes in parts of the herbicide binding environment induced by different treatments. In the case of a reduction-induced herbicide affinity change, the conformation of the binding environment could be affected by the reduction of aminoacid side chains in the binding protein. $\mathrm{Mg}^{2+}$ can directly modify the structure of the binding environment or indirectly via grana stacking. Since the herbicide binding protein(s) is expected to be rather surface-exposed (for example, the $32 \mathrm{kDa}$ polypeptide that can be labelled by azidoatrazine (the " $\mathrm{Q}_{\text {в }}$ protein") is attacked very easily by the protease trypsin) micro-environments in this protein complex could be altered by grana unstacking. The results obtained with $\mathrm{Mg}^{2+}$ omission and readdition are in line with previous findings that show significant effects of $\mathrm{Mg}^{2+}$ on the trypsinization patterns of PS II electron transport and its blockage by PS II herbicides [20].

Since replacement of $\mathrm{HCO}_{3}^{-}$by $\mathrm{HCOO}^{-}$is known to cause a large impairment of electron transport between $\mathrm{Q}_{A}$ and $\mathrm{Q}_{\mathrm{B}}$ [21], it is not surprising that $\mathrm{HCO}_{3}^{-}$also affects herbicide binding. The observa- tion that i-dinoseb and, for example, atrazine affinity behave qualitatively different upon $\mathrm{CO}_{2}$ depletion and readdition is in line with many other observations (also, see above) that the direct environments of the binding sites for atrazine and i-dinoseb do not behave similarly. The most striking difference in behaviour of atrazine and phenol-type inhibitors is found in triazine-resistant thylakoids in which the atrazine affinity is decreased by 3 orders of magnitude whereas the affinity of phenol-type inhibitors is increased considerably [12]. These effects are caused by a change in only one amino acid in the $32 \mathrm{kDa}$ " $\mathrm{Q}_{\mathrm{B}}$ protein" (J. Hirschberg et al., these proceedings).

Triazine-resistance also appears to differentially modify quinone affinity: the results presented here indicate that in triazine-resistant thylakoids the affinity of some quinones was decreased slightly whereas the tetrachloro- $p$-benzoquinone affinity is known to be increased considerably [10]. Assuming that, because of the large structural similarities between the different quinones, the binding sites for these quinones are (partially) overlapping, other determinants than only the quinone head group appear to modulate the quinone binding [10]. Not only quinone binding is modified in triazine-resistant thylakoids, but also the $\mathrm{Q}_{\overline{\mathrm{B}}}^{\overline{\mathrm{B}}}$ stabilization appears to be changed, resulting in a shifted equilibrium between $\mathrm{Q}_{\mathrm{A}}^{-} \cdot \mathrm{Q}_{\mathrm{B}}$ and $\mathrm{Q}_{\mathrm{A}} \cdot \mathrm{Q}_{\mathrm{B}}^{-}[10,22]$.

The amount of $\mathrm{PQ}-1$ needed to occupy half of the binding sites (PQ-1/PS II chain $=60$ in triazinesusceptible thylakoids) is higher than might be expected because the PQ pool that is filled by PS II consists of about 7 molecules per PS II chain in thylakoids [23]. Oettmeier and Soll very recently even reported that they could not observe herbicide displacement by PQ-1 addition without previous extraction of the native PQ [24]. The relative inefficiency of PQ-1 in herbicide displacement may indicate that added quinones do not partition uniformly into thylakoid membranes. Alternatively, the quinone binding site may be occupied by $\mathrm{Q}_{\mathrm{B}}$ in only part of the reaction chains [25], or the PQ-1 affinity for the site may be considerably lower than that of the native PQ-9.

The selective changes in inhibitor binding to the thylakoid suggest that the binding domains which regulate inhibitor binding can be selectively altered. There are two mechanisms by which these selective effects can occur. First, there may be multiple 
"allosteric" binding sites on the $\mathrm{Q}_{\mathrm{B}}$ protein (or even on adjacent polypeptides), such that binding at any of these sites causes a conformational change in the protein complex that limits the subsequent binding of unrelated inhibitors or the native PQ. The binding interaction between two related inhibitors or quinones, however, is expected to be competitive. The alternative model is that all inhibitors and PQ bind to a common domain, and thereby bind competitively. This "common site" model must imply the participation of many polypeptide side chain determinants in a binding site, such that these determinants can be selectively altered to give rise to the affinity changes summarized in this paper. However, the "common site" model cannot accommodate the observation that $\left[{ }^{14} \mathrm{C}\right]$ ioxynil and, to a lesser extent, $\left[{ }^{14} \mathrm{C}\right]$ atrazine binding is still possible after covalent linkage of an azidoquinone to the binding environment [6], unless it is assumed that the covalent quinone binding has changed the binding environment such that herbicide binding becomes possible, although with decreased affinity. No additional assumptions are required, however, to explain the herbicide binding data in the presence of covalently bound azidoquinone [6] and noncovalently bound 2-bromo-3-methyl-1,4-naphthoquinone [7] by the "allosteric" model. Again, it

[1] C. Fedtke, Biochemistry and Physiology of Herbicide Action, 1st edition, Springer Verlag, Berlin 1982.

[2] G. Renger, Biochim. Biophys. Acta 440, 287-300 (1976).

[3] B. R. Velthuys, FEBS Lett. 126, 277-281 (1981).

[4] C. A. Wraight, Isr. J. Chem. 21, 348-354 (1981).

[5] W. Tischer and H. Strotmann, Biochim. Biophys. Acta 460, 113-125 (1977).

[6] W. F. J. Vermaas, C. J. Arntzen, L.-Q. Gu and C. A. Yu, Biochim. Biophys. Acta 723, 266-275 (1983).

[7] K. Pfister, H. K. Lichtenthaler, G. Burger, H. Musso, and M. Zahn, Z. Naturforsch. 36 c, 645-655 (1981).

[8] H. Laasch, K. Pfister, and W. Urbach, Z. Naturforsch. 37 c, 620-631 (1982).

[9] W. F. J. Vermaas, Ph. D. Thesis, Agricultural University, Wageningen, The Netherlands 1984.

[10] W. F. J. Vermaas and C. J. Arntzen, Biochim. Biophys. Acta 725, 483-491 (1983).

[11] A. Trebst and W. Draber, Advances in Pesticide Science, Part 2 (H. Geissbühler, ed.), pp. 223-234, Pergamon Press, Oxford, New York 1979.

[12] K. Pfister and C. J. Arntzen, Z. Naturforsch. 34c, 996-1009 (1979).

[13] S. Shochat, G. C. Owens, P. Hubert, and I. Ohad, Biochim. Biophys. Acta 681, 21-31 (1982).

[14] R. Khanna, K. Pfister, A. Keresztes, J. J. S. van Rensen, and Govindjee, Biochim. Biophys. Acta 634, 105-116 (1981). should be stressed that also in this model allosteric interactions may only play a role between two different types of herbicides or between a herbicide and a quinone. The binding interaction between related herbicides or quinones is assumed to be truly competitive.

The final elucidation of a PS II inhibitor binding model will depend on a combined effort using protein chemistry coupled to both physiological assays and the use of a wide chemical range of inhibitors. Recent rapid advances in these fields offer encouragement that critical experiments can be conducted in the near future.

\section{Acknowledgements}

We thank May and Baker Ltd. (Ongar, England) for the gift of $\left[{ }^{14} \mathrm{C}\right]$ bromoxynil, CIBA-GEIGY (Greensboro NC, USA) for $\left[{ }^{14} \mathrm{C}\right]$ atrazine, Dr. C.-A. $\mathrm{Yu}$ (Oklahoma State University, Stillwater OK, USA) for 6-azido-5-decyl-2,3-dimethoxy- $p$-benzoquinone, and Dr. G. Hauska (Universität Regensburg, Regensburg, FRG) for PQ-1. This research would not have been possible without financial support by the Deutsche Forschungsgemeinschaft, the Deutsche Akademische Austauschdienst and CIBA-GEIGY.

[15] W. F. J. Vermaas, J. J. S. van Rensen, and Govindjee, Biochim. Biophys. Acta 681, 242-247 (1982).

[16] W. F. J. Vermaas, G. Renger, and G. Dohnt, Biochim. Biophys. Acta 764, 194-202 (1984).

[17] W. Oettmeier, K. Masson, and U. Johanningmeier, Proc. 5th Int. Congr. Photosynth. (G. Akoyunoglou, ed.), Vol. VI, pp. 585-594, Balaban Internat. Science Serv., Philadelphia 1981.

[18] J. J. S. van Rensen and W. F. J. Vermaas, Physiol. Plant. 51, 106-110 (1981).

[19] J. F. H. Snel and J. J. S. van Rensen, Physiol. Plant. 57, 422-427 (1983).

[20] G. Renger, R. Hagemann, and G. Dohnt, Biochim. Biophys. Acta 636, 17-26 (1981).

[21] W. F. J. Vermaas and Govindjee, Proc. Indian Natl. Sci. Acad. B47, 581-605 (1981).

[22] J. M. Bowes, A. R. Crofts, and C. J. Arntzen, Arch. Biochem. Biophys. 200, 303-308 (1980).

[23] H. H. Stiehl and H. T. Witt, Z. Naturforsch. 24b, $1588-1598$ (1969).

[24] W. Oettmeier and H.-J. Soll, Biochim. Biophys. Acta 724, 287-290 (1983).

[25] H. H. Robinson and A. R. Crofts, FEBS Lett. 153, 221-226 (1983). 